\title{
Estudio multimodal de hemangioma racemoso retiniano Archer 3
}

\section{Multimodal imaging of an Archer 3 retinal racemose hemangioma}

\section{Romana García-Gil*, Anselmo Feliciano-Sánchez, Lucía Ramos-González y Rafael Martínez-Costa}

Servicio de Oftalmología, Unidad de Tumores Oculares, Sección Retina Médica y Quirúrgica, Hospital Universitario y Politécnico La Fe, Valencia, España

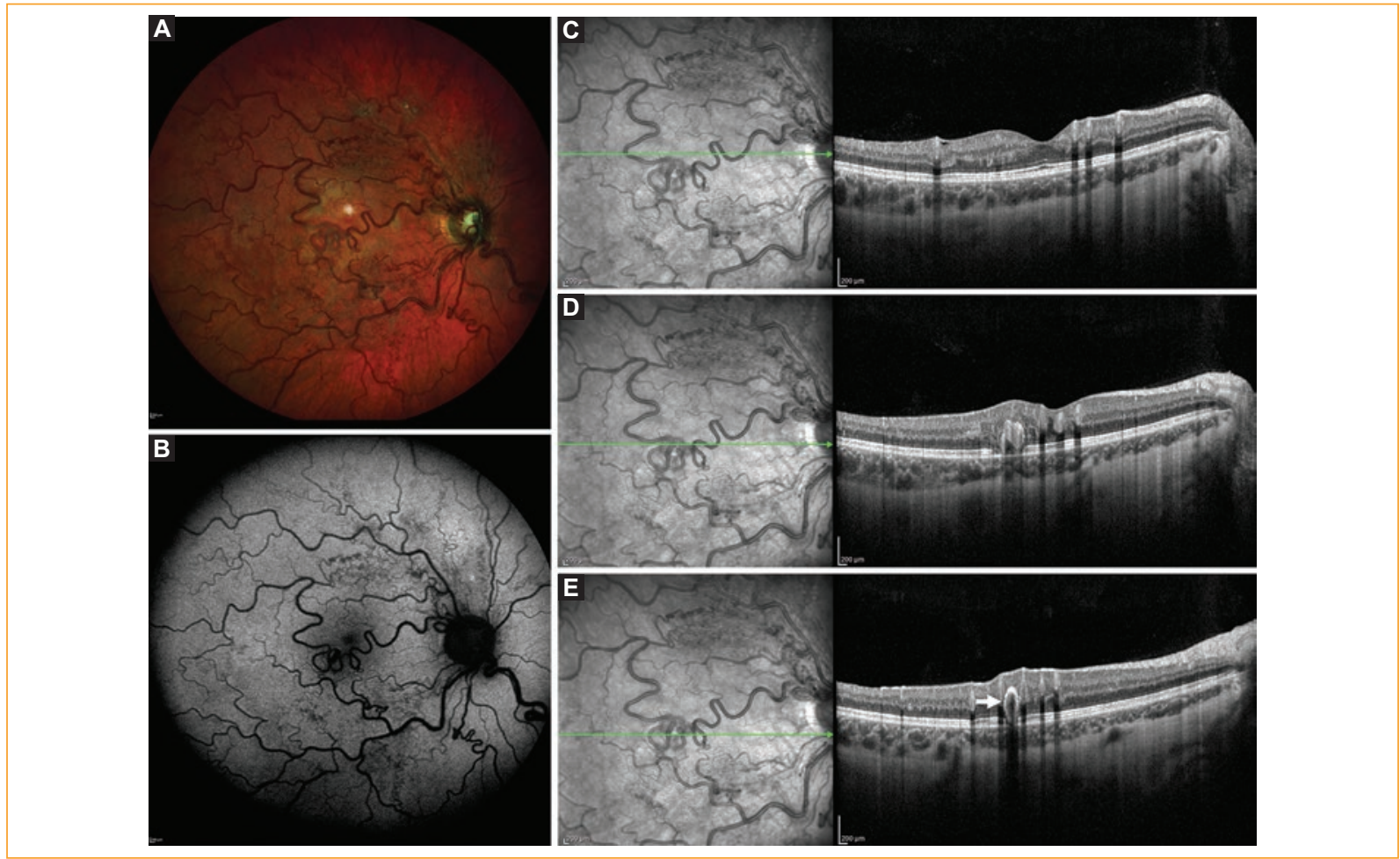

Figura 1. A: imagen multicolor de fondo de ojo. Se observan vasos retinianos dilatados y tortuosos, nacen del disco óptico y se extienden hacia la periferia retiniana como consecuencia de una comunicación arteriovenosa. B: autofluorescencia de onda corta. Se identifica con mayor definición el árbol vascular hipoautofluorescente que preserva el área foveolar; C, D y E: OCT. Se observa el perfil foveolar conservado (C), con irregularidades en la retina interna y externa, coincidiendo con la malformación vascular, estas provocan una sombra posterior (D), también puede apreciarse la luz vascular (E, flecha) y adelgazamiento coroideo.

Fecha de recepción: 04-07-2019 C.P. 46026, Valencia, España E-mail: romygg9@ hotmail.com
Disponible en internet: 07-11-2019 Rev Mex Oftalmol. 2020;94(2):98-99 www.rmo.com.mx 0187-4519/C 2019 Sociedad Mexicana de Oftalmología. Publicado por Permanyer México. Este es un artículo open access bajo la licencia CC BY-NC-ND (http://creativecommons.org/licenses/by-nc-nd/4.0/). 
Presentamos el caso de una mujer de 18 años, asintomática, con agudeza visual de 1 en ambos ojos. Presenta como hallazgo casual en el ojo derecho un hemangioma racemoso. Se trata es una malformación arteriovenosa retiniana de origen congénito, no hereditaria, que se engloba dentro de las facomatosis esporádicas.

El hemangioma racemoso de la retina se asocia en un $30 \%$ de los casos a malformaciones arteriovenosas cerebrales, lo que constituye el síndrome de Wyburn-Mason. En nuestro caso, la paciente no presentaba alteraciones vasculares sistémicas ni complicaciones oculares.

\section{Conflicto de intereses}

Los autores declaran que no existe conflicto de intereses.

\section{Responsabilidades éticas}

Protección de personas y animales. Los autores declaran que los procedimientos seguidos se conformaron a las normas éticas del comité de experimentación humana responsable y de acuerdo con la Asociación Médica Mundial y la Declaración de Helsinki.

Confidencialidad de los datos. Los autores declaran que han seguido los protocolos de su centro de trabajo sobre la publicación de datos de pacientes.

Derecho a la privacidad y consentimiento informado. Los autores han obtenido el consentimiento informado de los pacientes y/o sujetos referidos en el artículo. Este documento obra en poder del autor de correspondencia. 